Preventive Care in Nursing and Midwifery Journal

2019; 9(3): $1-9$

\title{
Investigating the Relationship between Work-Family Conflict (WFC) and Organizational Intelligence with the Mediating Role of Perceived Organizational Support and Job Performance of Nurses in Golestan Hospital of Ahvaz City, Khuzestan, Iran
}

\author{
Rasouli $\mathrm{N}^{1} \mathbb{\oplus}$, Heidari $\mathrm{A}^{2 *}$, Naderi $\mathrm{F}^{2}{ }^{\mathbb{D}}$, Marashian $\mathrm{FS}^{3} \mathbb{\oplus}$ \\ ${ }^{1} \mathrm{Ph} . \mathrm{D}$ Student, Department of Psychology, Ahvaz Branch, Islamic Azad University, Ahvaz, Iran \\ ${ }^{* 2}$ Associate Professor, Department of Psychology, Ahvaz Branch, Islamic Azad University, Ahvaz, Iran \\ ${ }^{3}$ Assistant Professor, Department of Psychology, Ahvaz Branch, Islamic Azad University, Ahvaz, Iran \\ “Corresponding Author: Department of Psychology, Ahvaz Branch, Islamic Azad University, Ahvaz, Iran.
}

Tel: 0098- 6133348420

Email: heidaria945@gmail.com

Received: 14 April $2020 \quad$ Accepted: 5 July 2020

\begin{abstract}
Background: Nurses constitute one of the most important occupational groups and pillars in organizations who provide healthcare services in all countries.

Objectives: The present study aimed to investigate the relationship between work-family conflict (WFC) and organizational intelligence with the mediating role of perceived organizational support and job performance of nurses.

Methods: The statistical population included all the nurses in Golestan hospital of Ahvaz city in 2019, 252 of which were selected as the sample of the study using convenience sampling. The research instruments included Paterson's Job Performance Questionnaire, the Work-Family Conflict Scale (WAFCS), the Organizational Intelligence Questionnaire, and Survey of Perceived Organizational Support (SPOS). The proposed model was evaluated using path analysis.

Results: A direct and negative relationship was observed between work-family conflict and job performance $(\beta=-0.456, P=0.000)$ and between work-family conflict and perceived organizational support $(\beta=-451$, $\mathrm{P}=0.000)$. There was a direct and positive relationship between organizational intelligence and perceived organizational support $(\beta=0.289, \quad \mathrm{P}=0.000)$ and between perceived organizational support and job performance $(\beta=0.204, \mathrm{P}=0.000)$. There was no direct and significant relationship between organizational intelligence and job performance among nurses $(\beta=0.092, \mathrm{P}=0.120)$. The path analysis results indicated that perceived organizational support had a mediating role in the relationship between work-family conflict and job performance $(\beta=-0.068, \mathrm{P}=0.008)$ as well as the one between organizational intelligence and job performance $(\beta=0.017, \mathrm{P}=0.012)$.

Conclusion: According to the results of this study, the proposed model was appropriate and can be considered as an important step towards identifying the factors affecting the job performance of nurses.
\end{abstract}

Keywords: family, intelligence, job performance, nurses, organizational support, work

\section{Introduction}

Nursing is characterized by being active for 24 hours a day, and by its nature, it is considered as a stressful job. Research has shown that the shift work nature of nursing has led to a number of negative impacts on family-related and social aspects. Moreover, this may also lead to the breakdown of common social activities with the spouse, endangering the mental health of nurses [1]. Work shifts cause social isolation, increased depression, and reduced mutual marital interactions, creating a risk for reduced quality of marital relations, which can result in reduced quality of job commitment and negatively 
influence the job performance of nurses [2]. Job performance is considered as one of the most fundamental concepts in organizations, based on which, the responsibilities and success of each individual are formed [3]. Lazaroiu [4] believes that job performance is a product of human behaviors, and motivations and needs affect the performance of individuals, and ultimately, the economic growth and development.

The work-family conflict (WFC) impacts the job performance of nurses. Achieving a stable balance between career and family life and managing the responsibilities of both in a satisfactory way have become one of the great challenges for employees in modern organizations [5]. Changes in family structure on the one hand and the increasing growth in international commercial competition on the other has blurred the lines between the two spheres of work and family. Simultaneously working in workplace and family will most likely lead to a type of intrapersonal conflict, which has become known as the work-family conflict (WFC). In terms of the outcomes of work-family conflict, the role played by personality characteristics and personal differences has gained especial attention in recent years. Personality can impact the behaviors and actions of individuals in the organization [6]. Ghislieri et al. [7] reported that personality characteristics could be significant predictors of a number of organizational outcomes such as attrition, loyalty, organizational commitment, the management of work-family conflict, and ultimately, the overall job performance of individuals. Various studies have confirmed the relationship between workfamily conflict and job performance of employees. Nowadays, organizations are facing broad changes in political, cultural, technological, and economic environments. A successful response of organizations in a highly dynamic and variable atmosphere significantly depends on their capability to provide data and identify optimal solutions for the problems they encounter. In such conditions, the organizational theorists and managers usually focus on the intellectual capability of the organization [8]. Organizational intelligence, as a mental ability, consists of components that affect all aspects of everyday life. Daňa et al. [9] believe that organizational intelligence, as a theoretical concept, has an important position in organizational theories.
Albrecht [10] states that organizational intelligence has seven main components:

1) strategic vision is the ability to create, infer, and communicate the goals of an organization.

2) shared fate is the feeling of having a shared goal among all the individuals in the organization to act and work in a synergic way.

3) appetite for change involves compatibility and tendency for change in order to realize the strategic vision.

4) mood refers to voluntary efforts of the members of the organization at a level above the expected level.

5) alignment and congruence include the presence of well-defined systems and rules for execution by individuals and groups in the organization.

6) knowledge deployment is the effective use of knowledge, information, and data.

7) performance pressure is including an executive position for each of the executives. Various studies have confirmed the relationship between organizational intelligence and job performance of employees [11,12]. A number of different studies have evaluated the direct relationship of work-family conflict (WFC) and organizational intelligence and job performance. However, the present study is the first to investigate the effects of the mediating factor of perceived organizational support in the above-mentioned relationship in order to assess the mediating role of variables in studies in a novel way. Perceived organizational support is associated with a large number of organizational variables including the relationship between the employee and his/her supervisor and providing rewards. Organizational support creates a positive and safe environment and leads to the loyalty of the individuals towards the organization [13]. The higher the perceived organizational support of the employees is, the better their performance becomes, and this increases their efficiency and results in their willingness to stay in the organization. Perceived organizational support reduces occupational pressure and intention to leave the organization. The supporting behaviors of the leaders and the organizational atmosphere can create the perceived supports [14]. In similar studies, Ghanbari et al. [15] and Bai [16] showed that perceived organizational support was related to job performance. In general, job performance is not only related to an individual's mental health 
but also to his/her productivity. Therefore, identifying the effective mechanisms to cope with mental pressures can be helpful in promoting mental health and boosting the efficiency and productivity of human resources. Reviewing the literature shows that perceived organizational support has been utilized as a predictor variable for job performance. Besides, in some cases, perceived organizational support has been used as the criterion variable for the variables of workfamily conflict (WFC) and organizational intelligence. The present study employs perceived organizational support as a mediating variable to determine how this variable affects work-family conflict (WFC) and organizational intelligence and consequently impacts the job performance of nurses. In a novel attempt, this study aimed to investigate the mediating role of perceived organizational support in the relationship between work-family conflict (WFC) and organizational intelligence and job performance of nurses in Golestan hospital of Ahvaz City, Khuzestan, Iran.

\section{Methods}

In order to achieve the objectives of the study, a correlation method was utilized, and path analysis was used to test the hypotheses. The statistical population of the study included all the nurses working in Golestan Hospital of Ahvaz City in 2019. Using convenience sampling, we administered 290 questionnaires measuring the variables of the study to the selected participants. The inclusion criteria were work experience over 6 months and participation consent. Ultimately, 252 questionnaires filled out by qualified participants were analyzed. In terms of ethical considerations, the participants gave their informed consent in which information confidentiality was ensured. The study was approved by the Ethics Committee of Islamic Azad University, Ahvaz branch (code: IR.IAU.AHVAZ.REC.1398.020).

\section{Research Instruments}

\section{Job Performance Questionnaire:}

The job performance questionnaire was developed by Paterson (1970), which includes 15 items to measure the job performance of employees. The scoring of the questionnaire is based on a 4-point Likert spectrum where scores of $0,1,2$, and 3 are given to options 'rarely', 'sometimes', 'often', and 'always', respectively. The scores for each participant can range from 0 to 45 . Higher scores indicate higher levels of job performance. The content validity of the questionnaire was confirmed by Shaghozaei et al. [17] and Rezapour [18], who reported a reliability of 0.82 and 0.87 based on Cronbach's Alpha coefficient, respectively. In the present study, in order to evaluate the internal consistency of the job performance questionnaire, a Cronbach's Alpha coefficient of 0.87 was obtained for the questions.

The Work-Family Conflict Scale (WAFCS): Carlson et al. [19] developed this scale in order to measure the variable of work-family conflict using 18 distinct items. The items in the questionnaire are scored based on a five-point Likert spectrum from 1 (completely disagree) to 5 (completely agree). In order to obtain the overall score for the questionnaire, the individual scores for every item are summed up. The highest possible overall score for the questionnaire is 90 , while the lowest possible overall score is 18 . Higher scores (close to 90) indicate the presence of a high WFC level, while lower scores (close to 18) indicate low levels of WFC. Carlson et al. [19] reported reliability coefficients of 0.78 to 0.87 using Cronbach's alpha coefficient for this questionnaire. Moreover, after translating the questionnaire into Persian and adapting it to the cultural conditions of Iran, Motesharrei et al. [20] and Fathipour \& Rasoulzadeh Aghdam [21] reported a high content validity for the questionnaire. In this study, the reliability of the questionnaire was found to be 0.81 using Cronbach's alpha coefficient.

The Organizational Intelligence Questionnaire: The Organizational Intelligence Questionnaire was developed by Albrecht [10] and consists of 49 items and 7 subscales. The scoring of this questionnaire is based on a five-point Likert spectrum from 1 to 5 , i.e., completely agree, agree, neither agree nor disagree, disagree, and completely disagree. The overall score for this questionnaire ranges from 49 to 245 . Higher the scores indicate higher organizational intelligence. The validity of this questionnaire was evaluated and confirmed by Baiakolaii et al. [22] and Keshavarz [23]. In order to evaluate its reliability, Cronbach's alpha coefficient was utilized, resulting in an overall coefficient of 0.93 . In the present study, the Cronbach's alpha coefficient was 0.86 for the questionnaire. 
Survey of Perceived Organizational Support: The Survey of Perceived Organizational Support (SPOS) was developed by Eisenberger et al. [24]. This survey includes 8 questions attempts to evaluate perceived organizational support. In this survey, in order to prevent bias in the answers, some of the questions are designed as negative and some as positive. The subscales are scored based on a 5-point Likert scale (from 1= completely disagree, to $5=$ completely agree) for positive questions and vice versa for negative questions. The overall score for this questionnaire ranges from 8 to 40 . Higher scores indicate higher levels of organizational intelligence. The reliability of this scale, using Cronbach's Alpha coefficient, was reported as 0.86 by Eisenberger et al [24]. This scale was translated into Persian by Zaki [25], who reported a reliability of 0.89 using Cronbach's Alpha coefficient for 100 participants. Moreover, the validity of this scale was confirmed by Oreizi et al [26] using exploratory and confirmatory factor analyses, which indicated the convergent and divergent validity for the scale. Furthermore, the unidimensionality of the scale was also confirmed by confirmatory factor analysis. In the present study, Cronbach's Alpha coefficient for the entire questionnaire was obtained to be 0.82 .

\section{Statistical analyses}

In the present study, we utilized descriptive statistical tests including mean, standard deviation, and Pearson's correlation coefficient. Cronbach's alpha coefficient was used for evaluating the reliability of the data collection tools. Moreover, in order to evaluate the fitness of the model, the indices including chi-square $\left(\chi^{2}\right)$, the ratio of chi-square to degree of freedom, Comparative Fit Index (CFI), Goodness of Fit
Index (GFI), Normed Fit Index (NFI), Incremental Fit Index (IFI), and Root Mean Square Error of Approximation (RMSEA) were used. Furthermore, in order to evaluate the mediating role, the percentile bootstrap method and bias-corrected bootstrap method were used. The analysis of the collected data was carried out using SPSS and AMOS software.

\section{Results}

The participants' average age was $38.46 \pm 7.81$. With regards to gender, 57.53 percent of the nurses participating in the study were females, and 42.47 percent were male nurses. With regards to educational level, 85.31 percent of the participants had a bachelor's degree, and 14.68 percent had a master's degree. Descriptive statistics including mean, standard deviation, and the list of variables of the study are presented in (Table 1).

Table 1: Descriptive statistics

\begin{tabular}{|c|c|c|c|}
\hline $\begin{array}{l}\text { Statistical indicators } \\
\text { Variables }\end{array}$ & $\mathbf{M}$ & SD & $\mathbf{n}$ \\
\hline Job performance & 25.33 & 12.68 & \multirow{4}{*}{252} \\
\hline Work-family conflict & 55.82 & 17.09 & \\
\hline Organizational intelligence & 109.89 & 44.27 & \\
\hline Perceived organizational support & 48.85 & 26.16 & \\
\hline
\end{tabular}

Descriptive statistics including mean, standard deviation, and the list of variables of the study are presented in Table 1. Moreover, the correlation matrix for the research variables is presented in (Table 2). According to the data of Table 2, the results of Pearson's correlation showed a significant relationship among all variables of the study $(\mathrm{P}<0.01)$.

Table 2: Pearson correlation coefficient among variables

\begin{tabular}{ccccc}
\hline Variables & $\mathbf{1}$ & $\mathbf{2}$ & $\mathbf{3}$ & $\mathbf{4}$ \\
\hline 1.Job performance & 1 & & & \\
\hline 2.Work-family conflict & $-0.575^{* *}$ & 1 & & \\
\hline 3.Organizational intelligence & $0.371^{* *}$ & $-0.447^{* *}$ & 1 & \\
\hline 4.Perceived organizational support & $0.469^{* *}$ & $-0.580^{* *}$ & $0.491^{* *}$ & 1 \\
\hline .01 & & & &
\end{tabular}

The Root Mean Square Error of Approximation index (RMSEA=0.441) showed that the preliminary model required correction (Table 3). In order to correct the model, the insignificant relationship between organizational intelligence and job performance was eliminated from the model. The results confirm the good fit of the model. 
Table 3: Initial and final model fit indicators

\begin{tabular}{cccccccc}
\hline Fit indicators & $\chi^{2}$ & df & $\left(\chi^{2} / \mathbf{d f}\right)$ & IFI & GFI & NFI & RMSEA \\
\hline Initial model & 0.000 & 0 & - & 1.000 & 1.000 & 0.999 & 0.441 \\
\hline Final model & 2.409 & 1 & 2.409 & 0.995 & 0.990 & 0.992 & 0.075
\end{tabular}

The findings in (Table 4) showed that the relationship between work-family conflict and job performance was negative and significant $(\beta=$ $0.456, \quad \mathrm{P}=0.000)$. There was no significant relationship between organizational intelligence and job performance among nurses $(\beta=0.092$, $\mathrm{P}=0.120$ ). There was a negative and significant relationship between work-family conflict and perceived organizational support in the nurses $(\beta=$ -451, $\mathrm{P}=0.000)$. There was a positive and significant relationship between organizational intelligence and perceived organizational support among the nurses $(\beta=0.289, \mathrm{P}=0.000)$. There was a direct and significant relationship between perceived organizational support and job performance of nurses $(\beta=0.204, P<0.000)$. In order to determine the significance of the mediating-based relations, the bootstrap method has been utilized.

Table 4: Path coefficients of direct effects between research variables in the initial and final model

\begin{tabular}{|c|c|c|c|c|c|c|}
\hline \multirow{2}{*}{ Path } & \multicolumn{3}{|c|}{ Initial model } & \multicolumn{3}{|c|}{ Final model } \\
\hline & Path type & $\boldsymbol{\beta}$ & P-value & Path type & $\boldsymbol{\beta}$ & P-value \\
\hline Work-family conflict to job performance & Direct & -0.434 & 0.000 & Direct & -0.456 & 0.000 \\
\hline Organizational intelligence to job performance & Direct & 0.092 & 0.120 & Direct & - & - \\
\hline Work-family conflict to perceived organizational support & Direct & -0.451 & 0.000 & Direct t & -0.451 & 0.000 \\
\hline Organizational intelligence to perceived organizational support & Direct & 0.289 & 0.000 & Direct & 0.289 & 0.000 \\
\hline Perceived organizational support to job performance & Direct & 0.172 & 0.172 & Direct & 0.204 & 0.000 \\
\hline $\begin{array}{l}\text { The indirect path from work-family conflict to job } \\
\text { performance through the mediating role of } \\
\text { perceived organizational support was significant } \\
(\beta=-0.068, P=0.008) \text {. Moreover, the indirect path }\end{array}$ & $\begin{array}{l}\text { from } \\
\text { perforr } \\
\text { percei } \\
(\beta=0.0\end{array}$ & $\begin{array}{l}\text { organiza } \\
\text { ance th } \\
\text { d organ } \\
7, \mathrm{P}=0.01\end{array}$ & $\begin{array}{l}\text { Ional it } \\
\text { pugh the } \\
\text { ational } \mathrm{s} \\
\text { (Table5) }\end{array}$ & $\begin{array}{l}\text { lligence } \\
\text { mediating }\end{array}$ & $\begin{array}{l}\text { to jc } \\
\text { role } \\
\text { gnifica }\end{array}$ & \\
\hline
\end{tabular}

Table 5: Results of the Bootstrap method for indirect and intermediary paths

\begin{tabular}{ccccccc}
\hline \multirow{2}{*}{ Predictor variable } & \multirow{2}{*}{ Mediator Variable } & \multirow{2}{*}{ Criterion variable } & \multicolumn{2}{c}{ Initial model } & \multicolumn{2}{c}{ Final model } \\
\cline { 3 - 6 } & & & Bootstrap & P-value & Bootstrap & P-value \\
\hline Work-family conflict & Perceived organizational support & Job performance & -0.058 & 0.010 & -0.068 & 0.008 \\
\hline Organizational intelligence & Perceived organizational support & Job performance & 0.014 & 0.013 & 0.017 & 0.012 \\
\hline
\end{tabular}

\section{Discussion}

There was a direct and negative relationship between WFC and job performance. In other words, as the WTC increased, the job performance of the employees decreased accordingly. Job performance is defined as those general values and discrete behavioral components an individual performs during a specific period of time. Improving and promoting the performance of the organization and increasing productivity in order to maximize the efficiency of human and material resources are among the important responsibilities of the managers and organizational leaders. In addition, a factor that seems to have a direct and undeniable impact on the effective performance of occupational duties involves having access to employees who are satisfied with their job and enjoy their occupational duties [27]. This is achieved through the mitigating role of WFC. The WFC develops when individuals are put in situations where they have to perform interfering roles requiring time, energy, and commitment. There was no positive significant relationship between organizational intelligence and job performance. This finding is inconsistent with the results of Alinia \& Hafezian, [11] and Ghareh et al [12]. However, by a closer examination, it was revealed that in the above-mentioned studies, the relationship between organizational intelligence and job performance was evaluated using correlation coefficient and regression tests, 
resulting in a significant relationship between the two variables. However, the present study evaluated the hypotheses based on path analysis. In this study, the relationship between organizational intelligence and job performance was significant based on Pearson's correlation coefficient as well. However, in the proposed model, due to the presence of a mediating variable, all the contribution and effects of the variable of organizational intelligence on job performance were explained through the mediating variable, namely an indirect relationship. In other words, in the current model, the variable of organizational intelligence impacts the job performance in an indirect manner. Therefore, this finding is somewhat in line with the results of previous studies. In other words, organizational intelligence has an indirect impact on job performance. This means that high organizational intelligence among nurses had a significant impact on their perceived organizational support, which, in turn, impacted their job performance. Nonetheless, it should be noted that the statistical populations of these studies differ significantly. In order to explain this finding, it can be said that in this turbulent and modern world, those individuals that have a high intelligence quotient become successful and efficient. Such individuals rely on their God-given intelligence to overcome life problems and challenges. This concept becomes more important when we recognize that in addition to the huge and creative source of human intelligence, intelligent mechanical tools play an important role in the performance of the organization as well. Therefore, in modern sophisticated organizations, organizational intelligence is the outcome of active human and artificial intelligence [12]. There is no doubt that in order to promote the dynamism and increase the efficiency of their organization, organizational managers have no choice but to utilize both of these intelligence streams. In addition, in this study, there was a direct and negative relationship between WFC and perceived organizational support. In general, stressful hospital environment reduces the time and energy of the individual to perform his/her family roles and the likelihood of enjoying family life activities such as attending family celebrations. Similarly, those nurses experiencing a high level of stress in their family environment do not have sufficient time and energy to perform their occupational duties and responsibilities. Therefore, they face difficulties in having a positive impact on their supervisors. As a consequence, such individuals cannot take advantage of rewards, benefits, and promotions, which can ultimately result in the individual's dissatisfaction with his/her job [28]. Therefore, stress in one sphere causes issues and problems in the other sphere, ultimately resulting in the individual's dissatisfaction. A large number of previous studies on WFC have shown that social support, both in the family and in the workplace, can mitigate the conflict developed between work and family and result in increased occupational and family satisfaction [26] by means of reducing WFC. Social support can have a direct impact on stressful occupational and family stimulants as well as other negatives outcomes caused by these stimulants, reducing the level of experienced pressure. Moreover, it can mitigate the effects of stressful stimulants in both spheres of occupational and family environments. Besides, we found a positive and direct relationship between organizational intelligence and perceived organizational support. As the organizational intelligence of nurses increased, their perceived organizational support increased as well. Organizations are always seeking new strategies to enhance the work efficiency of their employees [29]. Moreover, organizations need employees that have high levels of organizational intelligence, feel responsible and accountable, and can efficiently utilize the available resources. A high level of organizational intelligence of employees results in receiving organizational supports from the supervisors and superiors and increases their popularity in the organization for contributing to the dynamism and vitality of the organization [30]. Through creating access to various and diverse resources including information, emotional support, and financial support, perceived organizational support not only helps the individual achieve positive benefits and outcomes in both work and family spheres but also helps the individual better deal with the requirements and expectations of various roles they have to play. There was a positive relationship between perceived organizational support and job performance. Therefore, by increasing perceived organizational support 
among nurses, their job performance improved. This finding is consistent with the results of Ghanbari et al. [15] and Bai [16]. In order to explain this finding, it can be said that a high level of perceived organizational support led to commitment by the nurses to reciprocate these benefits and rewards, which can be expressed in the form of improved job performance. Since employees are the most important capital for any organization, the organization must provide comprehensive support for them. If the employees feel the support by their favorite organization, they are ensured that the organization will support them in task performance, conflict management, and/or in stressful situations [16]. As a consequence, these supported employees like to assume higher value and respect for the organization and to contribute to its goals and objectives. Perceived organizational support plays a mediating role in the relationship between WFC and job performance. Work-family conflict (WFC) among nurses increases their stress level and reduces physical health. In other words, increased WTC among employees results in reduced organizational support provided by the supervisors and weakened job performance among employees. Employees with higher levels of WFC have a lower flexibility and adaptability to their work conditions and work environment, which reduces their job performance. On the other hand, the attitudes of such employees towards their position and abilities as well as the value of their actions and activities extend to their family sphere, causing them to have an undesirable performance in that sphere similar to their workplace [31]. However, organizational support for these individuals can be effective in mitigating their WFC and improving their job performance. In other words, experiences, skills, and opportunities gained or improved in the organization (or in family life) will facilitate the participation of the individual in the organization (or in family life), resulting in the individual's satisfaction with his/her job and family [16]. Therefore, it can be concluded that the perceived organizational support has accurately been able to play a mediating role in the relationship between WFC and job performance. Perceived organizational support plays a mediating role in the relationship between organizational intelligence and job performance. Employees with higher levels of organizational intelligence become more active in utilizing resources and methods for advancing the goals of the organization. These individuals will enjoy the support of the managers and supervisors and will have a more desirable job performance [29]. Furthermore, organizational intelligence promotes and improves the individual accountability of the nurses in hospital environment. Therefore, when nurses have a high level of organizational intelligence in their workplace, which is characterized by diligence, commitment to occupational and job duties, responsiveness to patients and their companions, high level of accountability, and a collective spirit, they can obtain organizational support from their colleagues and supervisors due to their high levels of popularity. This, in turn, can improve their work conditions and job performance and minimize the stress caused by workload and shifts [9]. Therefore, it can be concluded that perceived organizational support was able to accurately play a mediating role in the relationship between organizational intelligence and job performance.

\section{Conclusion}

The main objective of the present study was to evaluate the mediating role of perceived organizational support in the relationship between WFC and organizational intelligence and the job performance of nurses working in hospitals in Ahvaz City, Khuzestan, Iran. In general, the results showed that all the direct paths, except for the path from organizational intelligence to job performance, were significant. Moreover, the indirect paths through perceived organizational support to job performance were significant as well. According to the results, the proposed model provided a good fit and is an important step towards identifying and understanding factors affecting job performance of nurses. This model can be considered as a good model to devise and design programs for preventing tensions experienced by nurses and can be useful in increasing their job performance. Besides, it is recommended that all stressful factors in both work and family spheres be identified, mitigated, or controlled. Moreover, training programs on improving skills and coping with stress can help reduce conflict and increase the satisfaction of employees with their jobs and families. Another 
measure that organizations can use to manage the conflict developed between the work and family of their employees is to adopt supportive policies such as flexible work schemes, opportunities for the employees to perform their parental duties, and supportive behaviors of colleagues and supervisors. Finally, through adopting the abovementioned strategies, organizations can not only reduce the interference between work and family but also pave the way for the individual's satisfaction with his/her job and family. On the other hand, in order to promote the awareness of managers and employees in terms of the role of intelligence in advancing personal and organizational goals, organizations can organize various training workshops. Using self-report questionnaires as data collection tools and selecting the sample from the nurses working in a single hospital were the main limitations of the present study, which may hinder the generalizability of our findings.

\section{Ethical considerations}

The study was approved by the Ethics Committee of Islamic Azad University, Ahvaz branch (IR.IAU.AHVAZ.REC.1398.020).

\section{Acknowledgements}

This article was extracted from a part of the $\mathrm{PhD}$ dissertation of Narges Rasouli in the Department of Psychology, Ahvaz Branch, Islamic Azad University, Ahvaz, Iran. We would like to thank all the nurses and employees of Golestan Hospital of Ahvaz City for their kind support.

\section{Conflict of interest}

The authors have no conflict of interest to declare.

\section{References}

1. Guo J, Chen J, Fu J, Ge X, Chen M, Liu Y. Structural empowerment, job stress and burnout of nurses in China. Appl Nurs Res. 2016; 31: 41- 45.

2. Orgambidez-Ramos A, Moura D, de Almeida $\mathrm{H}$. Role stress and psychological empowerment as antecedents of job satisfaction. Psicología. 2017; 35(1): 257- 79.

3. Bakhshi E, Kalantari R, Soleimani A, Salimi N. The study of burnout frequency and its association with job performance among healthcare staff. Prev Care Nurs \& Mid J (PCNM). 2017; 7(2): 58- 64.

4. Lazaroiu G. Employee Motivation and Job Performance. Linguistic and Philosophical Investigations. 2015; 14(1): 97- 102.
5. Derks D, Bakker AB, Peters P, Wingerden P. Work-related smartphone use, work-family conflict and family role performance: The role of segmentation preference. Hum Relat. 2016; 69(5): 1045- 68 .

6. Golparvar M, Andalib G. Role of Work-Family Facilitation on Family Satisfaction and Life Satisfaction among Female Nurses: Structural Equation Modeling. Prev Care Nurs \& Mid J (PCNM). 2016; 5(2): 42- 55. [In Persian]

7. Ghislieri C, Gatti P, Molino M, Cortese CG. Work-family conflict and enrichment in nurses: between job demands, perceived organisational support and work-family backlash. Nurs Manag. 2017; 25(1): 65- 75.

8. Carvalho AV, Esteban-Navarro M. Intelligence audit: Planning and assessment of organizational intelligence systems. J Librarianship and Inf Sci. 2016; 48(1): 47-59.

9. Daňa J, Caputo F, Ráček J. Complex Network Analysis for Knowledge Management and Organizational Intelligence. J Knowl Econ. 2018.

10. Albrecht K. Organizational Intelligence Profile: Preliminary Assessment Questionnaire. Re-thieved from Karl Albrecht International. 2002.

11. Alinia M, Hafezian M. The Mediator Role of Organizational Intelligence in the Relationship between the Quality of Information Technology and Job Performance of Employees. Information and Communication Technology in Educational Sciences. 2017; 8(1): 119- 39. [In Persian]

12. Ghareh M, Ferdosi M, Marashiyan F. The relationship between organizational intelligence and its components with Job performance on Board of Physical Education and Sport in Ahvaz city. Applied Research in Sport Management.2012; 1(2): 73- 80. [In Persian]

13. DeConinck JB, Moss HK, Deconinck MB. The relationship between servant leadership, perceived organizational support, performance, and turnover among business to business salespeople. Global $\mathbf{J}$ Management and Marketing. 2018: 2(1): 38- 52.

14. Zheng J, $\mathrm{Wu}$ G. Work-family conflict, perceived organizational support and professional commitment: A mediation mechanism for Chinese project professionals. Int $\mathrm{J}$ Environ Res Public Health. 2018; 15(2): 344.

15. Ghanbari S, Soltaninejad H, Badafara, M. Investigating the Impact of Perceived Organizational Support on Employee Job 
Performance (Study; Power Distribution Company). Quality and Productivity. 2018; 13(13): 144-49. [In Persian]

16. Bai N. Studying Relationship between Perceived Organizational Support and Job Performance of Golestan Province Physical Education Teachers. J Human Resource Management in Sport. 2017; 4(2): 189- 99. [In Persian]

17. Shaghozaei F, Marziyeh A, Nastezaei N. The Relationship of Professional Ethics with Social Competence and Job Performance Case Study: Staff of Zahedan Technical and Vocational Training Organization. Management Researches. 2018; 11(39): 117- 34. [In Persian]

18. Rezapour Y. Psychometric Characteristics of Work Domain Goal Orientation Questionnaire Farsi Version in Iranian Teachers. J Instruction and Evaluation, 2019; 11(44): 35- 54. [In Persian]

19. Carlson DS, Kacmar KM, Williams LJ. Construction and Initial Validation of a Multidimensional Measure of Work-Family Conflict. J Vocational Behavior. 2000; 56(2): 24976.

20. Motesharrei MH, Neisi AK, Arshadi A. The test of validity and reliability of Carlson, Kacmar \& Williams work-family conflict Questionnaire (2000). J Indust/OrgPsychol. 2013; 4(14): 65- 73.

21. Fathipour $P$, Rasoulzadeh Aghdam S. Evaluation of job and family-work conflict among employed women in governmental institutions of Tabriz. J Sociological Studies. 2017; 9(36): 4831. [In Persian]

22. Baiakolaii MM, Mirsepasi N, Delkhoshi A. Identification and explanation of organizational intelligence with knowledge management. Tose e Quarttely Development Management of The Human Resources and Logistics. 2014; 9(32): 119- 54. [In Persian]

23. Keshavarz L. Designing Relationship Model of cultural intelligence and Organizational
Intelligence at the Tehran's Taekwondo Boards. J Sport Management and Motor Behavior. 2018; 14(28): 111- 24. [In Persian]

24. Eisenberger R, Huntington R, Hutchison S, Sowa D. Perceived organizational support. J Applied psychology. 1986; 71(3): 500-7.

25. Zaki MA. Review and assessment of organizational support. J Admin Sci Econom, Univ Isfahan. 2006; 18(3): 103-23. [In Persian]

26. Oreizi H, Dibaji SM, Sadeghi M. investigation the relationship of work-family conflict with perceived organizational support, job stress and self-mastery in expatriate workers. Research in Clinical Psychology and Counseling. 2012; 1(2). 151-70. [In Persian]

27. Naeimi G, Nazari AM, Sanai Zaker B. A Study of relationship between Quality of Work Life and Work-Family Conflict with Job Performance among married men employee. Quarterly J Career \& Organizational Counseling. 2012; 4(10):57-72. [In Persian]

28. Shenavar F, Beshlideh K, Hashemi S E, Naami A. Considering the Mediating Role of Workfamily Conflict in Relationship between Stress and Social Support, and Job Satisfaction and Family Satisfaction. J Psychological Achievements. 2015; 22(1):111- 32. [In Persian]

29. Fu W. The impact of emotional intelligence, organizational commitment, and job satisfaction on ethical behavior of Chinese employees. J Business Ethics. 2014; 122(1): 137- 44.

30. Lamm E, Tosti-Kharas J, King CE. Empowering employee sustainability: Perceived organizational support toward the environment. J Business Ethics. 2015; 128(1); 207-20.

31. Rezaiee Ahvanuiee M, Nazari AM, Rasoli M. The Effect of Relationship Enhancement on Solving Dimensions of Work-Family Conflict. Preventive Care in Nursing \& Midwifery J. 2017; 7(1):8-17. 